\title{
Chitosan-Coated Magnetic Nanoparticles with Low Chitosan Content Prepared in One-Step
}

\author{
Yolanda Osuna, ${ }^{1}$ Karla M. Gregorio-Jauregui, ${ }^{1}$ J. Gerardo Gaona-Lozano, ${ }^{1}$ \\ Iliana M. de la Garza-Rodríguez, ${ }^{1}$ Anna Ilyna, ${ }^{1}$ Enrique Díaz Barriga-Castro, ${ }^{2}$ \\ Hened Saade, ${ }^{2}$ and Raúl G. López ${ }^{2}$ \\ ${ }^{1}$ Departamentos de Biotecnología y de Química Analítica, Facultad de Ciencias Químicas, Universidad Autónoma de Coahuila, \\ Boulevard V. Carranza y José Cárdenas Valdés, 25280 Saltillo, COAH, Mexico \\ ${ }^{2}$ Departamento de Procesos de Polimerización, Centro de Investigación en Química Aplicada, \\ Boulevard Enrique Reyna No. 140, 25294 Saltillo, COAH, Mexico
}

Correspondence should be addressed to Raúl G. López, glopez@ciqa.mx

Received 28 June 2012; Revised 4 September 2012; Accepted 5 September 2012

Academic Editor: Renyun Zhang

Copyright (C) 2012 Yolanda Osuna et al. This is an open access article distributed under the Creative Commons Attribution License, which permits unrestricted use, distribution, and reproduction in any medium, provided the original work is properly cited.

\begin{abstract}
Chitosan-coated magnetic nanoparticles (CMNP) were obtained at $50^{\circ} \mathrm{C}$ in a one-step method comprising coprecipitation in the presence of low chitosan content. CMNP showed high magnetization and superparamagnetism. They were composed of a core of $9.5 \mathrm{~nm}$ in average diameter and a very thin chitosan layer in accordance with electron microscopy measurements. The results from Fourier transform infrared spectrometry demonstrated that CMNP were obtained and those from thermogravimetric analysis allowed to determine that they were composed of $95 \mathrm{wt} \%$ of magnetic nanoparticles and $5 \mathrm{wt} \%$ of chitosan. $67 \%$ efficacy in the $\mathrm{Pb}^{+2}$ removal test indicated that only $60 \%$ of amino groups on CMNP surface bound to $\mathrm{Pb}$, probably due to some degree of nanoparticle flocculation during the redispersion. The very low weight ratio chitosan to magnetic nanoparticles obtained in this study, 0.053 , and the high yield of the precipitation reactions $(\approx 97 \%)$ are noticeable.
\end{abstract}

\section{Introduction}

Chitosan-coated magnetic nanoparticles constitute a very interesting material because of the number of actual and potential applications. This type of nanoparticles containing a core of a magnetic material, usually a mixture of magnetite $\left(\mathrm{Fe}_{3} \mathrm{O}_{4}\right)$ and maghemite $\left(\gamma-\mathrm{Fe}_{2} \mathrm{O}_{3}\right)$, owes its functionality to the free amino and hydroxyl groups that chitosan contains. Through these groups, CMNP are able to bind to a diversity of another chemical groups and ions which leads to a number of applications as protein and metal adsorption [1-3], guided drug and gene delivery $[4,5]$, magnetic resonance imaging [6], tissue engineering [7], and enzyme immobilization [8$10]$.

The most used procedure for CMNP preparing is first to obtain the magnetic nanoparticles, followed by chitosan coating $[2,8,11-13]$. CMNP with average diameters ranging from 14 [13] to $25-30 \mathrm{~nm}[2,11,12]$ and different chitosan contents have been prepared using this procedure. However, a few of papers have appeared in the specialized literature focused on preparing CMNP by a more simple onestep method, which basically includes coprecipitation in a solution containing $\mathrm{Fe}^{+2}, \mathrm{Fe}^{+3}$, and chitosan [14-16]. Using this method, CMNP with relatively large average particle diameter $(67 \mathrm{~nm})$ and 0.39 in theoretical weight ratio chitosan to magnetic nanoparticles were obtained [14]. Wu et al. [15] reported the preparation in one-step of CMNP with 50$100 \mathrm{~nm}$ in average diameter. Moreover, the theoretical weight ratio chitosan to $\mathrm{Fe}_{3} \mathrm{O}_{4}$ was as high as 8.7. The enormous difference between the weight ratios chitosan to magnetic nanoparticles in these reports is noticeable. Recently, our group reported the use of the one-step method to obtain CMNP, where magnetic nanoparticles showed $10-11 \mathrm{~nm}$ in average diameter and a weight ratio chitosan to magnetic nanoparticles in the composite between 0.06 and 0.24 [16]. It is noteworthy that these ratio values were significantly lower 
than those in the reports of Hong and Rhee [14] and $\mathrm{Wu}$ et al. [15]. Surprisingly, CMNP with the lowest chitosan content showed the highest $\mathrm{Pb}^{+2}$ ions removal efficacy from an aqueous solution containing a known concentration of $\mathrm{Pb}^{+2}$ ions. The proposed explanation for this was that particle aggregation and, as a consequence, a decrease in the total surface area available for $\mathrm{Pb}^{+2}$ binding, was favored by the use of higher chitosan contents during the magnetic nanoparticles precipitation. Based on these results, it would seem interesting to investigate on the preparation and characterization of CMNP with low chitosan content.

As a continuation of our previous work [16], we report here the preparation of CMNP in one-step with low content of chitosan. In fact, we used the lowest chitosan concentration of those used in our previous work, which would lead to a theoretical weight ratio chitosan to magnetic nanoparticles close to 0.06 . The product of the process was characterized in detail and a discussion on the implications of the preparation of CMNP in one-step with low content of chitosan was included.

\section{Materials and Methods}

2.1. Materials. Chitosan with low molecular weight and $75 \%$ deacetylation degree, ferric chloride $\left(\mathrm{FeCl}_{3} \cdot 6 \mathrm{H}_{2} \mathrm{O}, 99 \%\right)$, ferrous chloride $\left(\mathrm{FeCl}_{2} \cdot 4 \mathrm{H}_{2} \mathrm{O}, 98 \%\right)$, aqueous ammonia $\left(\mathrm{NH}_{4} \mathrm{OH}, 57.6 \mathrm{wt} \%\right)$ and ninhydrine (97\%) from Aldrich were used as received. Lead nitrate, $\mathrm{Pb}\left(\mathrm{NO}_{3}\right)_{2}, 99.7 \%$, from J. T. Baker, was also used as received. Deionized and tripledistilled water was drawn from a Millipore system.

\subsection{Preparation of Coated Magnetic Nanoparticles. CMNP} were prepared in duplicate (runs C1 and C2) in a $150 \mathrm{~mL}$ jacketed glass reactor equipped with a reflux condenser, an inlet for aqueous ammonia feed and a mechanical agitator operated at $400 \mathrm{rpm}$. To carry out the reaction, $50 \mathrm{~mL}$ of $\mathrm{FeCl}_{3} \cdot 6 \mathrm{H}_{2} \mathrm{O}(0.32 \mathrm{M})$ and $50 \mathrm{~mL}$ of $\mathrm{FeCl}_{2} \cdot 4 \mathrm{H}_{2} \mathrm{O}(0.2 \mathrm{M})$ were mixed in the reactor. Then, $0.125 \mathrm{~g}$ of chitosan was added to the mixture and the temperature was raised to $50^{\circ} \mathrm{C}$. Coprecipitation reaction without chitosan was also carried out in duplicate (runs M1 and M2) as a control. Once $\mathrm{Fe}^{+2}$, $\mathrm{Fe}^{+3}$ and chitosan solution reached the desired temperature, the dosing of $20 \mathrm{~mL}$ of the aqueous ammonia at $0.67 \mathrm{~mL} / \mathrm{min}$ was started. After dosing was over, the completion reaction was allowed to proceed for $20 \mathrm{~min}$. At the end of the reaction, the particles were recovered by using a permanent magnet, washed 25 times with deionized water, and lyophilized to obtain the final product.

2.3. Nanocomposites Characterization. X-ray analysis of the products was carried out with a Siemens D-5000 diffractometer using $\mathrm{Cu}-\mathrm{K}_{\alpha}(\lambda=1.5418 \AA)$ as incident radiation. The size and morphology of the particles were determined in a JEOL JSM-7401F scanning-transmission electron microscope (STEM) and a high-resolution transmission electron microscopy (HRTEM) Titan- $300 \mathrm{kV}$, for which samples were prepared by dispersing the resulting powders in water with ultrasonication and then depositing the dispersion on a copper grid. The magnetic properties of the nanoparticles were determined using a Physical Properties Measurement System from Quantum Design, model 6000 in mode vibrating sample magnetometer (VSM), with an applied field between -20.0 and $20.0 \mathrm{kOe}$ at room temperature. Fourier transform infrared spectrometry (FTIR) was carried out in a Magna IR 550 from Nicolet with germanium crystal. Thermogravimetric analysis (TGA) of nanoparticles and chitosan was performed in a TGA Q500 from TA Instruments. Analyzed samples were heated from 30 to $800^{\circ} \mathrm{C}$ at a heating rate of $10^{\circ} \mathrm{C} / \mathrm{min}$ under a nitrogen flow of $50 \mathrm{~mL} / \mathrm{min}$. The amino groups on the surface of CMNP were determined by the ninhydrin method, using glycine to construct the calibration curve [17]. To make the measurements, $0.1 \mathrm{~g}$ of CMNP were dispersed in $1 \mathrm{~mL}$ of water and then $0.6 \mathrm{~mL}$ of ninhydrin reagent were added. After that, the dispersion temperature was boiled for $30 \mathrm{~min}$. The amino groups concentration in the dispersion was determined by readings of absorbance at $570 \mathrm{~nm}$.

2.4. $\mathrm{Pb}^{+2}$ Removal Test. Typically, $60 \mathrm{mg}$ of dried CMNP were added to $50 \mathrm{~mL}$ of $10 \mathrm{ppm} \mathrm{Pb}\left(\mathrm{NO}_{3}\right)_{2}$ aqueous solution. Then, this mixture was ultrasonicated for $50 \mathrm{~min}$ at room temperature taking samples during the process each $10 \mathrm{~min}$. After CMNP were removed, the concentration of $\mathrm{Pb}^{+2}$ in the samples was measured by atomic absorption spectroscopy in a Varian SpectrAA 220 equipment.

\section{Results and Discussion}

There was no visual difference detected between the appearance of the product of the reactions carried out with and without chitosan. In both cases, a black powder was obtained. The X-ray diffraction pattern (XRDP) of the products obtained with chitosan (run C1) and without chitosan (run M1) are shown in Figure 1. XRDPs from the replicates (runs C2 and M2) were not included; however, they show the same signals pattern. Figure 1 also includes the standard patterns of magnetite and maghemite, which were taken from the library of our X-ray equipment. This obeys to the fact that precipitation reactions from $\mathrm{Fe}^{+2}+\mathrm{Fe}^{+3}$ aqueous solutions using aqueous ammonia usually render a mixture of magnetite and maghemite $[18,19]$. As it can be seen in Figure 1, XRDPs of magnetite and maghemite display the same signals pattern in the range 30 to $752 \theta^{\circ}$. However, the maghemite pattern shows a signal at $18.222 \theta^{\circ}$, which is not displayed by the magnetite pattern. XRDPs from the products of runs $\mathrm{C} 1$ and $\mathrm{M} 1$ display the characteristic signals of magnetite and maghemite patterns in the range 30 to 75 $2 \theta^{\circ}$. However, they also show the $18.222 \theta^{\circ}$ signal. From these data, it might be thought that the magnetic nanoparticles are composed only of maghemite. However, the product is not brown, the characteristic color of maghemite, but black, the color of magnetite [20]. Thus, based on the XRDPs of the precipitation products along the product color, it is concluded that the magnetic nanoparticles are composed of a mixture of magnetite and maghemite.

An estimation of the average grain sizes of the magnetic nanoparticles obtained in the precipitation reactions can be 


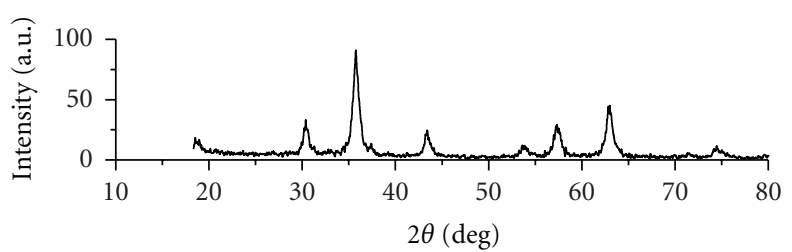

(a)

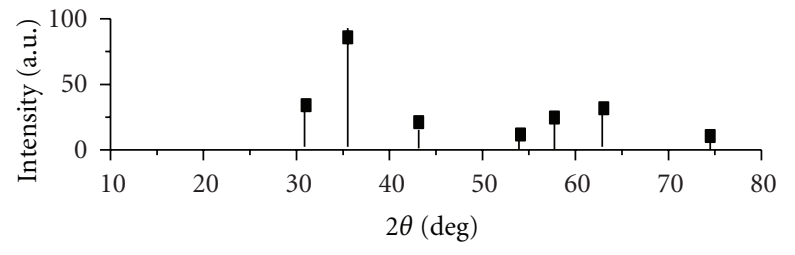

(c)

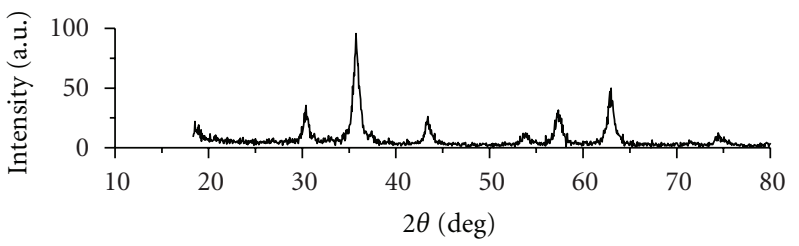

(b)

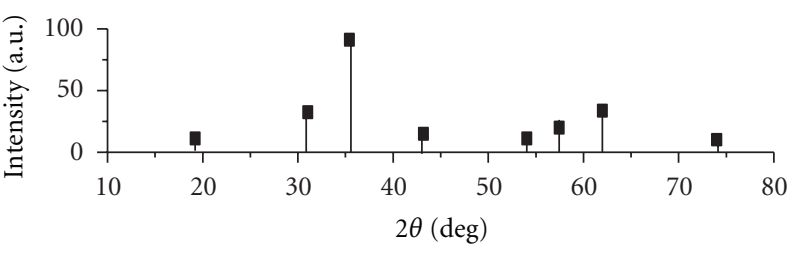

(d)

FigURE 1: X-ray patterns of magnetic nanoparticles prepared by coprecipitation method: (a) without chitosan and (b) with 0.125 (w/v\%) of chitosan. It also included (c) magnetite standard pattern and (d) maghemite standard pattern.

obtained by using data from their XRDPs and the wellknown Scherrer equation, which is represented as:

$$
d=\frac{K \lambda}{\beta \cos \theta},
$$

where $d$ is the average diameter of grain in $\mathrm{nm}$; $K$ is the dimensional factor $(0.9) ; \lambda$ is the $\mathrm{X}$-ray wavelength $(0.154 \mathrm{~nm}) ; \beta$ is the line broadening at half the maximum intensity in radians, and $\theta$ is the Bragg's angle. $d$ values obtained were $13.05 \pm 0.31$ for nanoparticles prepared with chitosan and $12.60 \pm 0.00 \mathrm{~nm}$ for naked magnetic nanoparticles. From these results, it is evident that the presence of chitosan during precipitation reaction does not affect the grain size of magnetic nanoparticles.

Figure 2 shows STEM micrographs of nanoparticles prepared without and with chitosan (Figures 2(a) and 2(b), resp.). Measurements of more than 1000 nanoparticles from different micrographs of each of the samples were carried out by using an image analysis program (Image $1.37 \mathrm{c}$ ). These results were used to construct the corresponding histograms of particle diameters, also included in Figure 2. In addition, using the data from nanoparticle size measurements, the number-average diameter $\left(D_{n}\right)$ was calculated with the following equation [21]:

$$
D_{n}=\frac{\sum n_{i} D_{i}}{\sum n_{i}}
$$

where $n_{i}$ is the number of particles of diameter $d_{i}$.

STEM micrographs in Figure 2 show nanoparticles with spheroidal morphology. A difference between naked nanoparticles and those prepared with chitosan was not visually detected in this figure, however, a HRTEM micrograph of a single nanoparticle prepared with chitosan (Figure 3), shows that a chitosan layer on magnetic nanoparticles was formed. In this figure, the crystal planes of the nanoparticle can be identified as parallel lines crossing the particle image. However, these lines do not extend to the edges of the nanoparticle. Instead, there is a central area (bounded by a red line in the image), which includes the crystal planes, that is, those of the magnetic nanoparticle. The remaining area near the edges of the nanoparticle, that does not include the crystal planes, would correspond to an amorphous substance, in this case, chitosan. It is remarkable the very thin layer of chitosan on the magnetic nanoparticle, which is in accordance with that expected because of the chitosan low content in the recipe.

$D_{n}$ values of naked nanoparticles and those prepared with chitosan were $9.5 \pm 0.1$ and $9.9 \pm 0.2 \mathrm{~nm}$, respectively. In spite that coprecipitation is a widely used method for preparing magnetic nanoparticles, it is not common obtaining nanoparticles with average diameters smaller than $10 \mathrm{~nm}$, as those reported in this work. In fact, the average diameters of magnetic nanoparticles prepared by coprecipitation method range from 14 [13] to $25-30 \mathrm{~nm}[2,11,12]$. Although, it cannot be excluded that other authors using this method have obtained magnetic nanoparticles with similar sizes to those obtained in this work, they were not identified in our search in the specialized literature.

A comparison of the magnetic nanoparticles size determined from STEM with the average grain size estimated by using (1) indicates that the latter is slightly higher than the former. However, taking into account that Scherrer equation gives a rough estimation of the average grain size of the material, it can be said that the size of magnetic nanoparticles and that of the grains are similar. In turn, this would lead to conclude that the magnetic nanoparticles are composed of only one grain, even when chitosan was present during the precipitation reaction.

Figure 4 shows the magnetization curves at room temperature of the nanoparticles obtained with and without chitosan. These curves were prepared using the averages of the magnetization values from the products obtained in the reactions and their replicates. The magnetization of naked nanoparticles attained a value of $73.2 \pm 1.7 \mathrm{emu} / \mathrm{g}$ at the maximum magnetic field applied $(20 \mathrm{kOe})$, while that of nanoparticles obtained in the presence of chitosan was $65.6 \pm 0.1 \mathrm{emu} / \mathrm{g}$. These values are similar to those 

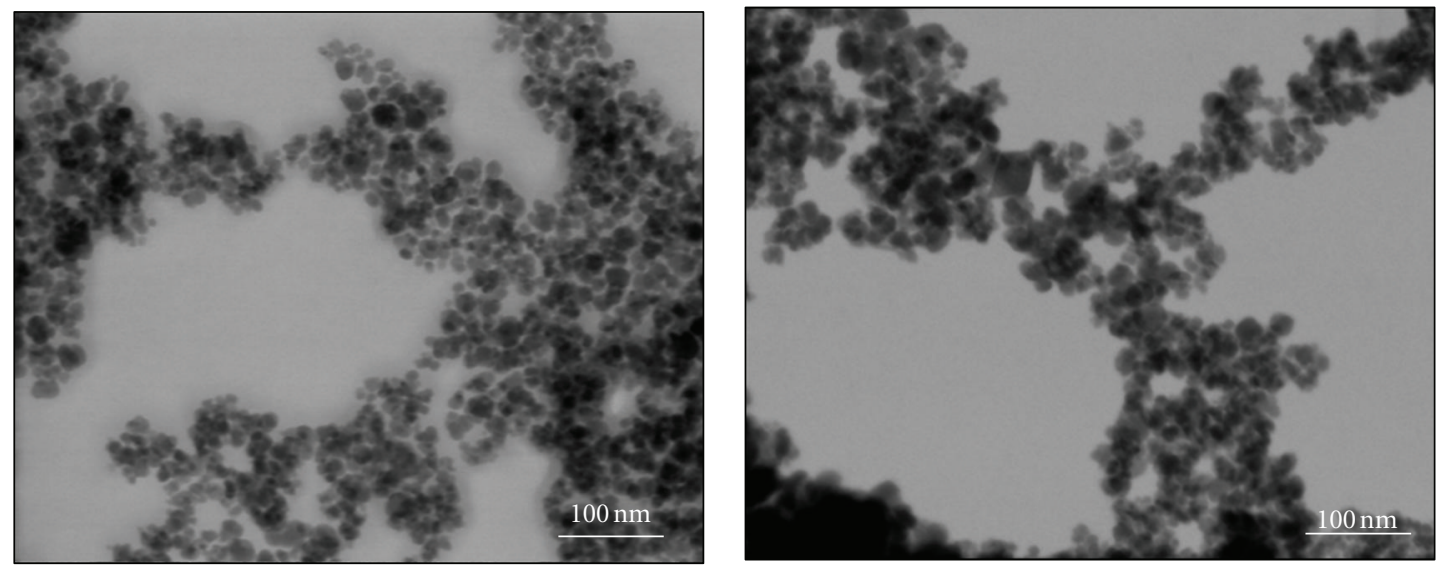

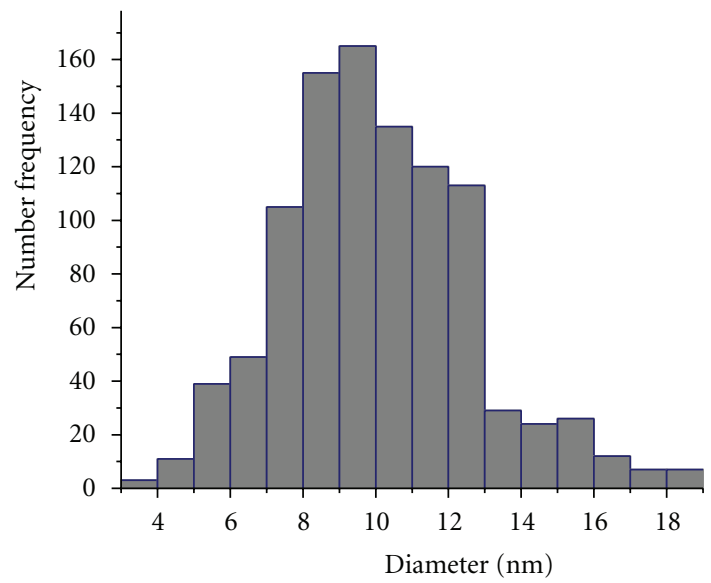

(a)

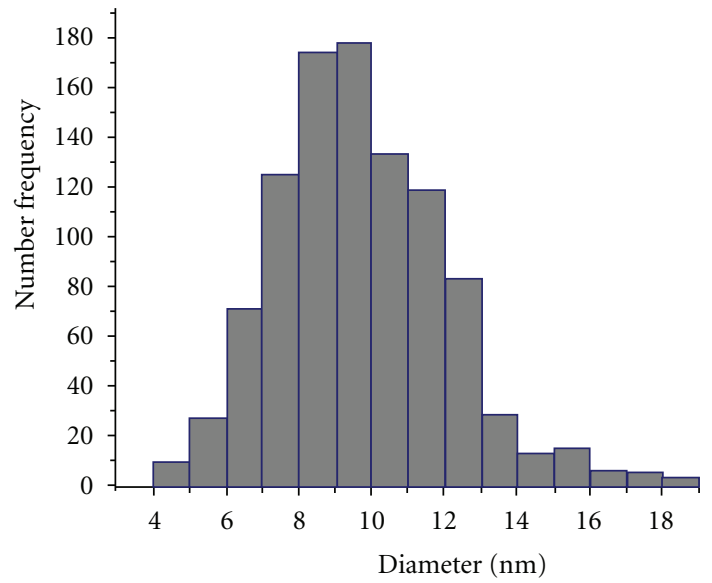

(b)

FIGURE 2: SEM micrographs of particles prepared by coprecipitation method (a) without chitosan and (b) with 0.125 (w/v\%) of chitosan. Corresponding nanoparticle diameter histograms are also included.

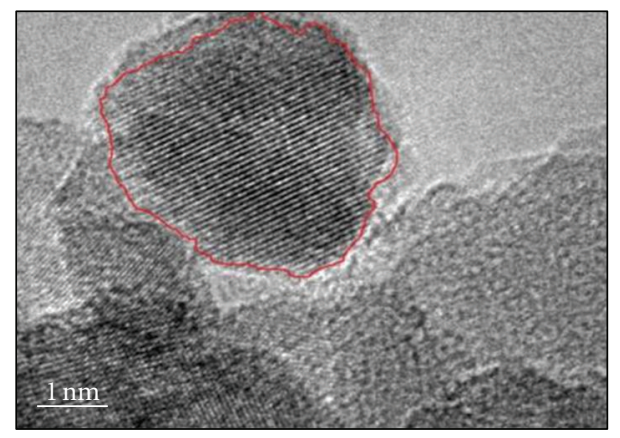

FIGURE 3: HRTEM micrograph of a nanoparticle prepared by coprecipitation method with 0.125 (w/v\%) of chitosan. The red line delimits the extension of the crystalline region of the nanoparticle.

reported for the naked magnetic nanoparticles and CMNP with $0.125 \%(\mathrm{w} / \mathrm{v})$ of chitosan in the formulation in our previous work [16]. Statistically, it can be said that naked nanoparticles magnetized more than those prepared with chitosan, which is ascribed to the fraction of nonmagnetic material (chitosan) that the nanoparticles would contain. It is noteworthy that the curves in Figure 4 do not attain magnetic saturation values. This is explained as a consequence of the difficulty for aligning the magnetic moments in the direction of applied magnetic field experimented by the surface atoms, which constitute a significant fraction of the total atoms in very small particles [22]. It is also noticeable the very low values of remnant magnetization and coercivity field of prepared nanoparticles. Naked nanoparticles attained $1.6 \pm$ $0.3 \mathrm{emu} / \mathrm{g}$ and $17.8 \pm 2.7$ Oe in remnant magnetization and coercivity field, respectively, while the corresponding values for the magnetic nanoparticles prepared with chitosan were $1.5 \pm 0.9 \mathrm{emu} / \mathrm{g}$ and $22.7 \pm 3.8$ Oe. These values are very small and indicate a superparamagnetic behavior, which is characteristic of magnetite and maghemite nanoparticles with diameters smaller than $10-15 \mathrm{~nm}$ [23]. The most attractive feature of superparamagnetic nanoparticles is their demagnetization once the applied magnetic field is removed, which allows their reuse.

For comparison purposes, it is mentioned that the final magnetization value of the naked nanoparticles prepared in this study is higher than those reported by Ge et al. [13] and 


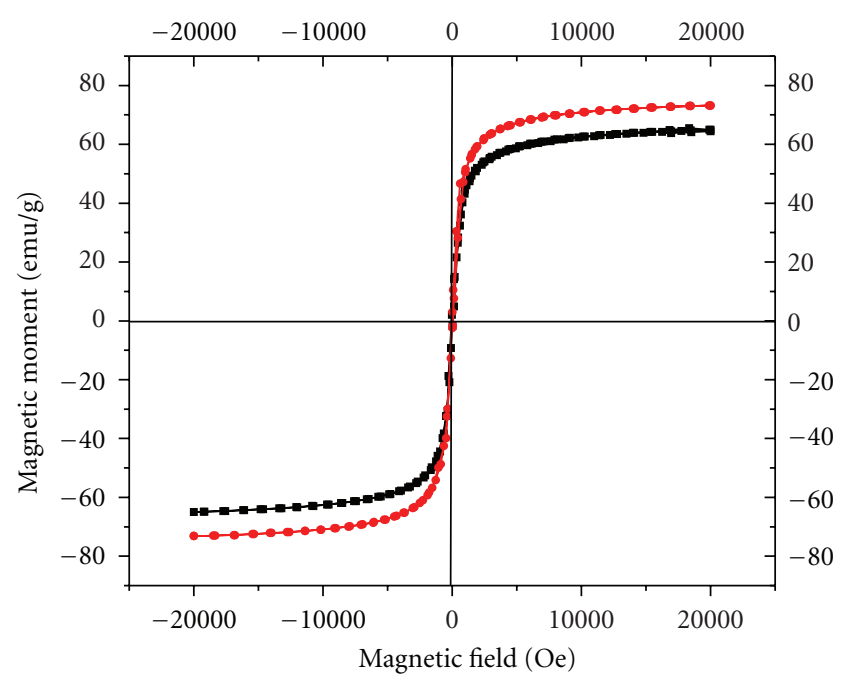

Figure 4: Magnetization curves determined at room temperature for nanoparticles prepared by coprecipitation method: $(\bullet)$ without chitosan and ( $\mathbf{\square})$ with $0.125(\mathrm{w} / \mathrm{v} \%)$ of chitosan.

Wu et al. [15], similar to that obtained by Pan et al. [12] but lower than those reported by Liu et al. [2] and Kuo et al. [8]. The latter authors obtained values of magnetic saturation around $80 \mathrm{emu} / \mathrm{g}$, however, due to the relatively large size of the nanoparticles ( $\approx 25 \mathrm{~nm}$ in average diameter) [2], they showed a relatively high values of remnant magnetization. This characteristic would lead to nanoparticles agglomeration after the magnetic field removal, which is not attractive for some applications where the re-use of the nanoparticles is required. On the other hand, CMNP obtained in this study show final magnetization values similar to those reported by other authors $[8,12,13]$ and higher than that reported by Wu et al. [15], who obtained a value of $35.5 \mathrm{emu} / \mathrm{g}$.

The direct dependence between magnetization of small particles (diameters smaller than ca. $15 \mathrm{~nm}$ ) and particle size $[24,25]$ is well known. Because of this, it is noticeable the relatively high values of final magnetization obtained in this study, taking into account that the sizes of the corresponding magnetic nanoparticles are in the bottom of the sizes range reported in the literature on preparation of magnetic nanoparticles by coprecipitation method $[2,8,11-$ 15]. Considering that magnetization in magnetic nanoparticles directly depends on crystallinity [26], the higher magnetization values obtained in this study could be ascribed to a possible improvement in the magnetic nanoparticles crystallinity.

Figure 5 shows the FTIR spectra of pure chitosan and magnetic nanoparticles prepared with chitosan (run C1). The spectrum of the product from run $\mathrm{C} 2$ (not shown) displays a similar signals pattern to that from run C1. In accordance with that reported in the literature [27, 28], the characteristic absorption bands for chitosan in Figure 5 appear at 3457 (O-H and $\mathrm{N}-\mathrm{H}$ stretching vibrations), 2875 (C-H stretching vibrations), 1658 ( $\mathrm{N}-\mathrm{H}$ bending vibrations), 1425 (C-N stretching vibrations) and $1076 \mathrm{~cm}^{-1}$ (C-O-C stretching vibrations). The spectrum of the product obtained

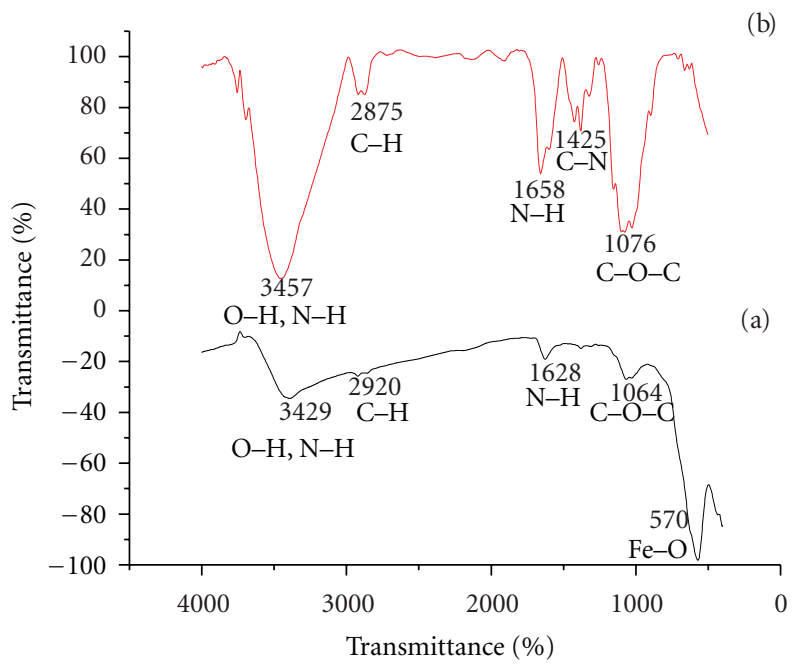

FIGURE 5: FTIR spectra of nanoparticles prepared by (a) coprecipitation method with $0.125(\mathrm{w} / \mathrm{v} \%)$ of chitosan and (b) that of pure chitosan.

using chitosan show four of the five characteristic absorption bands for this polymer (signal at $1425 \mathrm{~cm}^{-1}$ disappeared) and one additional at $570 \mathrm{~cm}^{-1}$, which corresponds to Fe$\mathrm{O}$ stretching vibrations in magnetite and maghemite [8]. Considering that the products of the precipitation reactions in presence of chitosan were exhaustively washed and magnetically recovered, free chitosan, if there was, was removed. Thus, it was concluded that all the chitosan in the final product is chemically bound to the magnetic nanoparticles. FTIR spectra results demonstrated that the precipitation reactions carried out with chitosan rendered magnetic nanoparticles coated by this polymer.

The results of TGA characterization of CMNP (run C1), naked nanoparticles (run M1), and pure chitosan are shown in Figure 6. From these measurements and those of the replicates, an average weight loss of $91.52 \pm 0.03 \%$ was calculated for CMNP, while naked nanoparticles and pure chitosan showed weight losses of $3.98 \pm 0.13$ and $96.39 \pm$ $0.40 \%$, respectively. From these results and the weight of the CMNP samples before and after TGA characterization, a content of $5.0 \pm 0.3 \mathrm{wt} \%$ of chitosan in CMNP was estimated, which equals to $52.6 \mathrm{mg}$ of chitosan immobilized on one gram of magnetic nanoparticles or 0.053 in weight ratio chitosan to magnetic nanoparticles. The theoretical value of immobilized chitosan calculated from the recipe of precipitation reactions, assuming that the reaction proceeded to $100 \%$ and only magnetite was obtained, was $64.4 \mathrm{mg} / \mathrm{g}$ or 0.065 in weight ratio chitosan to magnetic nanoparticles. Furthermore, it is interesting to mention that the weight of the final product recovered from runs $\mathrm{C} 1$ and $\mathrm{C} 2$ was 1.9800 and $1.9880 \mathrm{~g}$, respectively. Considering the chitosan and magnetic nanoparticles content in CMNP as determined from the results by TGA and assuming that the precipitation reactions render only magnetite, it was estimated a yield close to $96.7 \%$ for both of precipitation reactions. Also, it was estimated that only around $76 \%$ of the chitosan in the recipe 


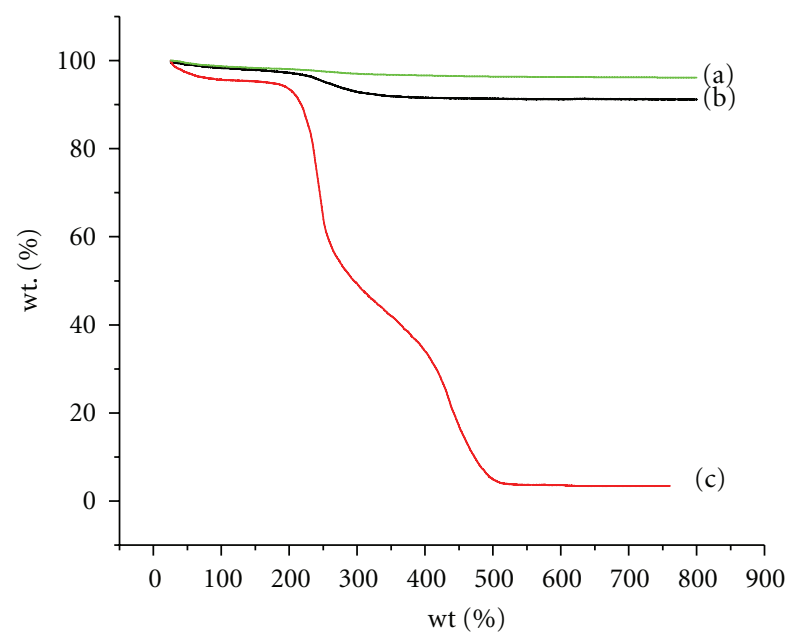

Figure 6: Thermal degradation curves of nanoparticles prepared by coprecipitation method: (a) without chitosan and (b) with 0.125 $(\mathrm{w} / \mathrm{v} \%)$ of chitosan. It is also included that of (c) pure chitosan.

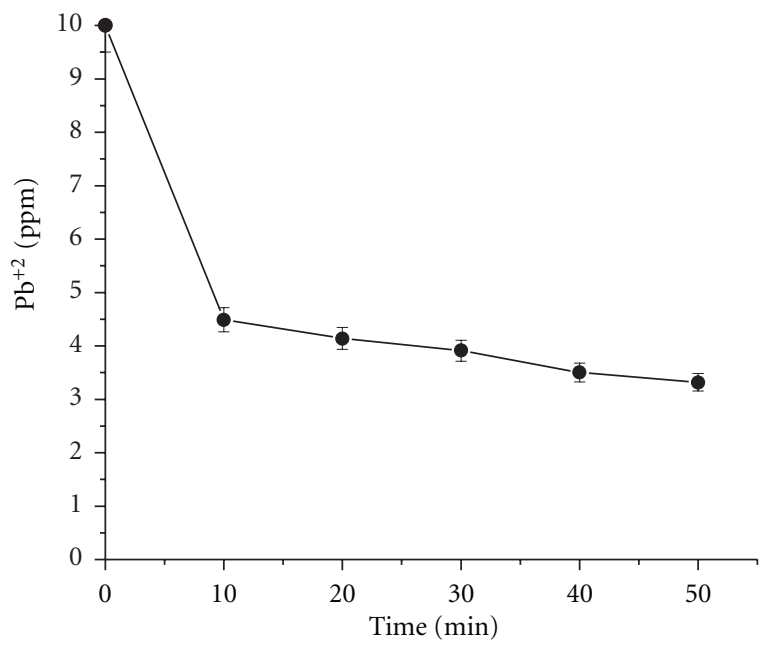

Figure 7: $\mathrm{Pb}^{+2}$ removal as a function of time using chitosan-coated magnetic nanoparticles prepared by coprecipitation method with $0.125 \%(\mathrm{w} / \mathrm{v})$ of chitosan.

was covering the magnetic nanoparticles for CMNP from run $\mathrm{C} 1$ and $84 \%$ for those from run $\mathrm{C} 2$. This is the reason why the experimental value of immobilized chitosan is less than the theoretical one.

To verify the reacting availability of the amino groups on the surface of CMNP, an evaluation of their efficacy for $\mathrm{Pb}^{+2}$ removal from a $\mathrm{Pb}\left(\mathrm{NO}_{3}\right)_{2}$ aqueous solution was carried out. This test is based on the ability of chitosan to chelate heavy metal ions through its amino groups. The average results of the behavior of CMNP from runs $\mathrm{C} 1$ and $\mathrm{C} 2$ are shown in Figure 7. This figure shows that the $\mathrm{Pb}^{+2}$ concentration drops from its initial value $(10 \mathrm{ppm})$ to around $4.5 \mathrm{ppm}$ in the first 10 minutes. Then, it slowly decreases to attain a final value of $3.22 \mathrm{ppm}$ at the end of the test, which equals to a removal efficacy of $67.8 \%$. In spite that this value looks interesting, it is only a part of the picture. It still remains unclear if all or only a fraction of the amino groups on the CMNP surface bound to $\mathrm{Pb}^{+2}$ ions. To elucidate this, it was proceeded as follows. TGA results allowed to estimate that CMNP was composed of $95 \mathrm{wt} \%$ of magnetic nanoparticles and $5 \mathrm{wt} \%$ of chitosan. From TEM measurements, a $D_{n}$ value of $9.5 \mathrm{~nm}$ for magnetic nanoparticles was determined. With these data and density values of $5.2 \mathrm{~g} / \mathrm{mL}$ for magnetite [29] and $1.342 \mathrm{~g} / \mathrm{mL}$ for chitosan [30], it was estimated that one gram of CMNP contains $4.07 \times 10^{17}$ nanoparticles and that the chitosan layer on a magnetic nanoparticle is close to $0.3 \mathrm{~nm}$ in thickness. The latter result implies that CMNP have an average diameter around $10.1 \mathrm{~nm}$, which roughly agrees with that determined from TEM measurements $(9.9 \mathrm{~nm})$. On the other hand, ninhydrin method allowed to estimate that one CMNP gram contained 0.0911 mmoles of amino groups distributed on their surface. With this amount and considering that one CMNP gram is composed of $4.07 \times 10^{17}$ nanoparticles, a value of 135 amino groups per each coatedmagnetic nanoparticle was obtained. Simple calculations from results obtained in the $\mathrm{Pb}^{+2}$ removal test, indicate that $3.39 \times 10^{-4} \mathrm{~g}$ of $\mathrm{Pb}^{+2}$ ions were chelated by the CMNP in the test. This value along that of nanoparticle number contained in one gram of CMNP lead to an estimation of $40 \mathrm{~Pb}^{+2}$ ions chelated by each coated-magnetic nanoparticle and, from here, 3.4 amino groups per each $\mathrm{Pb}^{+2}$ ion. Taking into account that two amino groups are required to chelate one $\mathrm{Pb}^{+2}$ ion, it is concluded that only around $60 \%$ of amino groups were used in the chelation process. Now, the question is why an important fraction of the amino groups, $40 \%$, on the surface of CMNP is not able to chelate $\mathrm{Pb}^{+2}$ ions. An explanation to this behavior would arise from an incomplete redispersion of CMNP, previously recovered as a powder, during the $\mathrm{Pb}^{+2}$ removal test. If so, a fraction of CMNP would form clusters of flocculated nanoparticles, which would reduce the available CMNP area, and as a consequence, the available amino groups for chelating $\mathrm{Pb}^{+2}$ ions.

\section{Conclusions}

Superparamagnetic nanoparticles composed of a magnetitemaghemite mixture with relatively high magnetization final values were precipitated in the presence of chitosan. This one-step method allowed to obtain CMNP, which consist of a magnetic nanoparticle core of $9.5 \mathrm{~nm}$ in average diameter coated by a thin layer of chitosan. From the TGA results it was calculated that CMNP were composed of $5 \mathrm{wt} \%$ of chitosan and $95 \mathrm{wt} \%$ of magnetic nanoparticles, and that the chitosan layer on a magnetic nanoparticle was close to $0.3 \mathrm{~nm}$ in thickness. In the $\mathrm{Pb}^{+2}$ removal test, CMNP showed a efficacy close to $68 \%$, which implies that only $60 \%$ of the amino groups on the surface of CMNP bound to $\mathrm{Pb}^{+2}$ ions. The explanation for this behavior arose from a possible CMNP flocculation, which would lead to a reduction in the available amino groups for chelating $\mathrm{Pb}^{+2}$ ions. Finally, the very low weight ratio chitosan to magnetic nanoparticles obtained in this study, 0.053, is remarkable, which is almost the minimum necessary to cover each nanoparticle, considering that the polymer is homogeneously distributed. 


\section{Acknowledgments}

National Council of Science and Technology (CONACyT) supported this paper through Grant 2007-84009. The authors are grateful to Blanca Huerta and Julieta Sánchez for their technical assistance in characterization work.

\section{References}

[1] L. Zhu, J. Ma, N. Jia, Y. Zhao, and H. Shen, "Chitosan-coated magnetic nanoparticles as carriers of 5-Fluorouracil: preparation, characterization and cytotoxicity studies," Colloids and Surfaces B, vol. 68, no. 1, pp. 1-6, 2009.

[2] X. Liu, Q. Hu, Z. Fang, X. Zhang, and B. Zhang, "Magnetic chitosan nanocomposites: a useful recyclable tool for heavy metal ion removal," Langmuir, vol. 25, no. 1, pp. 3-8, 2009.

[3] Y. T. Zhou, H. L. Nie, C. Branford-White, Z. Y. He, and L. M. $\mathrm{Zhu}$, "Removal of $\mathrm{Cu}^{2+}$ from aqueous solution by chitosancoated magnetic nanoparticles modified with $\alpha$-ketoglutaric acid," Journal of Colloid and Interface Science, vol. 330, no. 1, pp. 29-37, 2009.

[4] L. Li, D. Chen, Y. Zhang et al., "Magnetic and fluorescent multifunctional chitosan nanoparticles as a smart drug delivery system," Nanotechnology, vol. 18, no. 40, Article ID 405102, pp. 40-51, 2007.

[5] H. Zhang, M. Oh, C. Allen, and E. Kumacheva, "Monodisperse chitosan nanoparticles for mucosal drug delivery," Biomacromolecules, vol. 5, no. 6, pp. 2461-2468, 2004.

[6] S. Hong, Y. Chang, and I. Rhee, "Chitosan-coated ferrite $\left(\mathrm{Fe}_{3} \mathrm{O}_{4}\right)$ nanoparticles as a T2 contrast agent for magnetic resonance imaging," Journal of the Korean Physical Society, vol. 56, no. 3, pp. 868-873, 2010.

[7] T. Sasaki, N. Iwasaki, K. Kohno et al., "Magnetic nanoparticles for improving cell invasion in tissue engineering," Journal of Biomedical Materials Research A, vol. 86, no. 4, pp. 969-978, 2008.

[8] C.-H. Kuo, Y.-C. Liu, C.-M. J. Chang, J.-H. Chen, C. Chang, and C.-J. Shieh, "Optimum conditions for lipase immobilization on chitosan-coated $\mathrm{Fe}_{3} \mathrm{O}_{4}$ nanoparticles," Carbohydrate Polymers, vol. 87, no. 4, pp. 2538-2545, 2012.

[9] W. Xie and J. Wang, "Immobilized lipase on magnetic chitosan microspheresfor transesterification of soybean oil," Biomass and Bioenergy, vol. 36, pp. 373-380, 2012.

[10] H. Fang, J. Huang, L. Ding, M. Li, and Z. Chen, "Preparation of magnetic chitosan nanoparticles and immobilization of laccase," Journal Wuhan University of Technology, Materials Science Edition, vol. 24, no. 1, pp. 42-47, 2009.

[11] D. T. K. Dung, T. H. Hai, L. H. Phuc, B. D. Long, L. K. Vinh, and P. N. Truc, "Preparation and characterization of magnetic nanoparticles with chitosan coating," Journal of Physics, vol. 187, no. 1, Article ID 012036, pp. 1-5, 2009.

[12] C. Pan, B. Hu, W. Li, Y. Sun, H. Ye, and X. Zeng, "Novel and efficient method for immobilization and stabilization of $\beta$-dgalactosidase by covalent attachment onto magnetic $\mathrm{Fe}_{3} \mathrm{O}_{4}$ chitosan nanoparticles," Journal of Molecular Catalysis B, vol. 61, no. 3-4, pp. 208-215, 2009.

[13] Y. Ge, Y. Zhang, S. He, F. Nie, G. Teng, and N. Gu, "Fluorescence modified chitosan-coated magnetic nanoparticles for high-efficient cellular imaging," Nanoscale Research Letters, vol. 4, no. 4, pp. 287-295, 2009.

[14] S. Hong and I. Rhee, "Relaxivity of hydrogen protons of water molecules in the aqueous solutions of dextran and chitosan coated ferrite nanoparticles," International Journal of Magnetic Resonance Imaging, vol. 1, no. 1, pp. 15-20, 2007.

[15] Y. Wu, Y. Wang, G. Luo, and Y. Dai, "In situ preparation of magnetic $\mathrm{Fe}_{3} \mathrm{O}_{4}$-chitosan nanoparticles for lipase immobilization by cross-linking and oxidation in aqueous solution," Bioresource Technology, vol. 100, no. 14, pp. 3459-3464, 2009.

[16] K. M. Gregorio-Jauregui, M. G. Pineda, J. E. Rivera-Salinas et al., "One-step method for preparation of magnetic nanoparticles coated with chitosan," Journal of Nanomaterials, vol. 2012, Article ID 813958, 8 pages, 2012.

[17] E. Kaiser, R. L. Colescott, C. D. Bossinger, and P. I. Cook, "Color test for detection of free terminal amino groups in the solid-phase synthesis of peptides," Analytical Biochemistry, vol. 34, no. 2, pp. 595-598, 1970.

[18] J. Esquivel, I. A. Facundo, M. E. Treviño, and R. G. López, "A novel method to prepare magnetic nanoparticles: precipitation in bicontinuous microemulsions," Journal of Materials Science, vol. 42, no. 21, pp. 9015-9020, 2007.

[19] A. L. Loo, M. G. Pineda, H. Saade, M. E. Treviño, and R. G. López, "Synthesis of magnetic nanoparticles in bicontinuous microemulsions. Effect of surfactant concentration," Journal of Materials Science, vol. 43, no. 10, pp. 3649-3654, 2008.

[20] P. A. Dresco, V. S. Zaitsev, R. J. Gambino, and B. Chu, "Preparation and properties of magnetite and polymer magnetite nanoparticles," Langmuir, vol. 15, no. 6, pp. 1945-1951, 1999.

[21] E. A. Collins, Emulsion Polymerization and Emulsion Polymers, John Wiley and Sons, Baffins Lane, Chichester, UK, 1997.

[22] R. H. Kodama, "Magnetic nanoparticles," Journal of Magnetism and Magnetic Materials, vol. 200, no. 1, pp. 359-372, 1999.

[23] R. M. Cornell and U. Schwertmann, The Iron Oxides: Structure, Properties, Reactions, Occurrence and Uses, Wiley-VCH, Weinheim, Germany, 1996.

[24] L. Liz, M. A. López Quintela, J. Mira, and J. Rivas, "Preparation of colloidal $\mathrm{Fe}_{3} \mathrm{O}_{4}$ ultrafine particles in microemulsions," Journal of Materials Science, vol. 29, no. 14, pp. 3797-3801, 1994.

[25] S. Santra, R. Tapec, N. Theodoropoulou, J. Dobson, A. Hebard, and W. Tan, "Synthesis and characterization of silicacoated iron oxide nanoparticles in microemulsion: the effect of nonionic surfactants," Langmuir, vol. 17, no. 10, pp. 2900 2906, 2001.

[26] H. Qi, J. Ye, N. Tao, M. Wen, and Q. Chen, "Synthesis of octahedral magnetite microcrystals with high crystallinity and low coercive field," Journal of Crystal Growth, vol. 311, no. 2, pp. 394-398, 2009.

[27] L. Guo, G. Liu, R. Y. Hong, and H. Z. Li, "Preparation and characterization of chitosan poly(acrylic acid) magnetic microspheres," Marine Drugs, vol. 8, no. 7, pp. 2212-2222, 2010.

[28] L. Chen, C. Y. Tang, N. Y. Ning, C. Y. Wang, Q. Fu, and Q. Zhang, "Preparation and properties of chitosan/lignin composite films," Chinese Journal of Polymer Science, vol. 27, no. 5, pp. 739-746, 2009.

[29] P. E. Liley, R. C. Reid, and E. Buck, "Physical and Chemical Data," in Chemical Engineering Handbook, R. H. Perry, D. W. Green, and J. O. Maloney, Eds., Section 3, pp. 3-11, McGrawHill Book, New York, NY, USA, 6th edition, 1984.

[30] W. C. Hsieh, C. P. Chang, and S. M. Lin, "Morphology and characterization of 3D micro-porous structured chitosan scaffolds for tissue engineering," Colloids and Surfaces B, vol. 57, no. 2, pp. 250-255, 2007. 

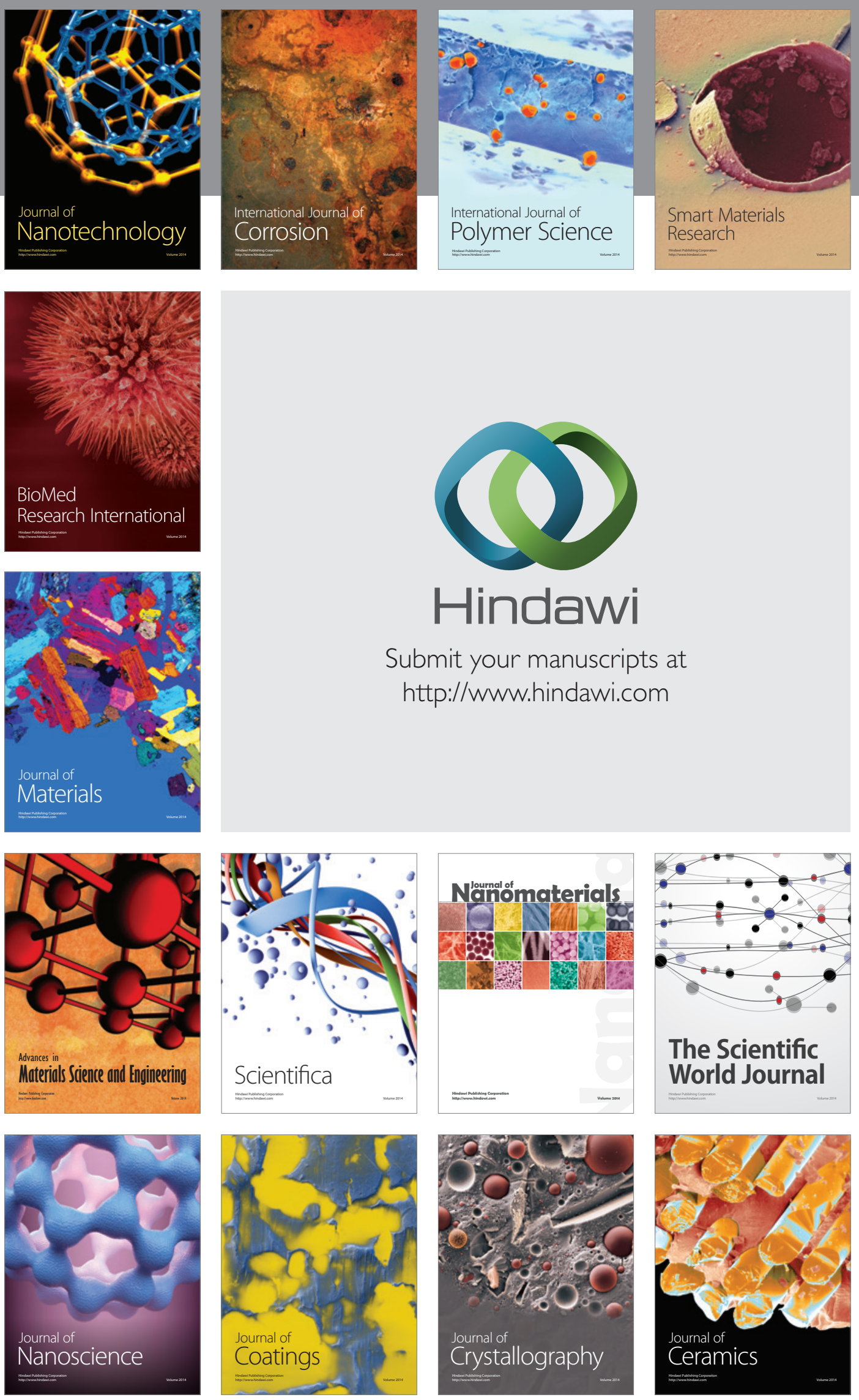

The Scientific World Journal

Submit your manuscripts at

http://www.hindawi.com

\section{World Journal}

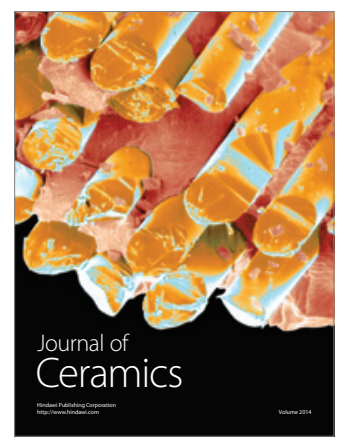

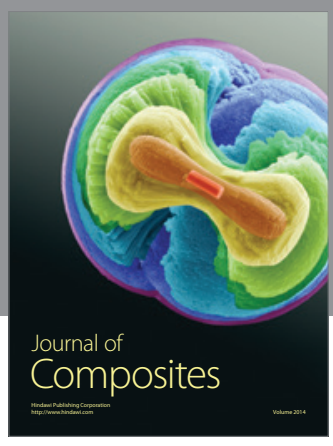
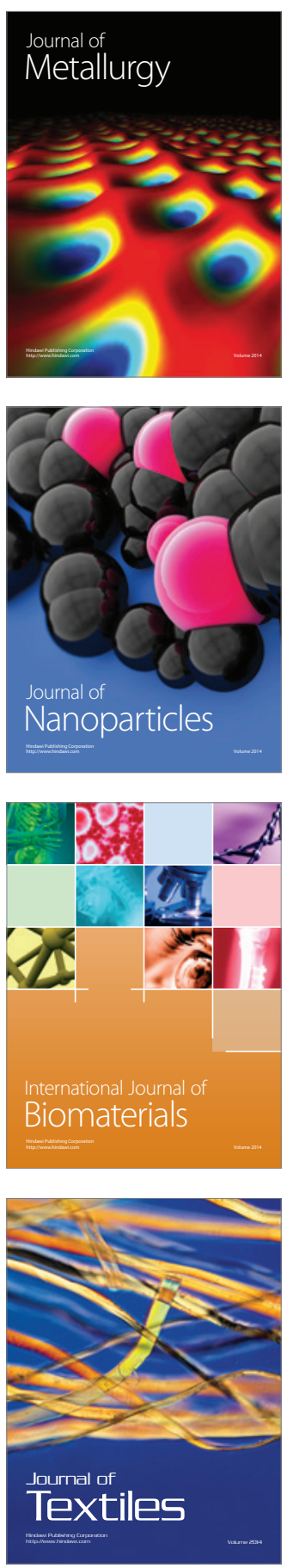